\title{
STRENGTHENING AND REPAIRING OF RC DEEP BEAMS USING CFRP AND GFRP
}

\author{
Amr H. Zaher \\ Structural Engineering Department, Faculty of Engineering, \\ Ain Shams University, Cairo, Egypt \\ Wael M. Montaser \\ Construction and Building Department, Faculty of Engineering, \\ October 6 University, Giza, Egypt \\ Mahmoud M. Elsonbaty \\ Construction and Building Department, Faculty of Engineering, \\ October 6 University, Giza, Egypt
}

\begin{abstract}
There are many reasons to upgrade an existing structure such as building code changes, accidents, design errors or building use changes. Few years ago the construction industry began using fibre reinforced polymer (FRP) for structural reinforcement, typically in combination with other building materials such as wood, steel and concrete. FRP show multiple attractive properties, such as low weight to strength ratio, non-corrosiveness high fatigue strength, and case of application. This study investigated different techniques to improve the performance of $R C$ deep beams under two concentrated vertical loads using advanced composite materials (CFRP and GFRP sheets). The primary aim of this research was to study the behaviour of deep beams strengthened and repaired in shear using carbon and glass fibres. Thirteen RC deep beam specimens were simply supported with span lengths $L=1500$ $\mathrm{mm}$ and cross sections $140 \times 450 \mathrm{~mm}$. The tested beams were subjected to the effects of two concentrated loads with spacing of 560, 360 and $160 \mathrm{~mm}$ and were divided into five groups. The test results show that the deep beams strengthened by CFRP sheets \& GFRP sheets provided improvement in ultimate loads. The maximum increase in ultimate loads reached $106 \%$ \& $81 \%$ respectively and the decrease in deflection for beams was attributed to the type, configurations and orientation of the FRP sheets. An analytical model was done based on code equations to predict the deformational behaviour of RC deep beams shear-strengthened with FRP composites, and obtain the failure loads by using three codes equations and compare the results with the experimental results, The proposed analytical model gave good compliance with the experimental results .
\end{abstract}

Keywords: deep beams, reinforced concrete, shear span to depth ratio a/d, CFRP sheets, GFRP sheets. 
Cite this Article: Amr H. Zaher, Wael M. Montaser, Mahmoud M. Elsonbaty, Strengthening and Repairing of RC Deep Beams using CFRP and GFRP. International Journal of Civil Engineering and Technology 11(1), 2020, 64-85.

http://iaeme.com/Home/issue/IJCIET?Volume=11\&Issue=1

\section{INTRODUCTION}

Reinforced concrete (RC) deep beams are considered useful in tall buildings, offshore structures, long-span structures, and complex foundation systems. The moment capacities of deep beams are normally adequate and are not of major concern, but the shear capacity of deep beams is very important to understand since properly designed deep beams usually fail in shear at the ultimate limit state. Deep beams are characterized by relatively small values of span to depth ratios. Because of their proportions, they develop a mechanism of force transfer quite different from that in shallow beams.

Different values of the span to depth ratio (Le/d) and the shear span to depth ratio (a/d) are proposed by different design codes to define deep beams. The American Concrete Institute (ACI) code (2005) and the Egyptian code define a beam as a deep beam when the effective span to depth ratio (Le/d) is less than 4 , and the Canadian code defines deep beams with Le/d less than 1.25 for simple beams.

As RC deep beams have become important structural elements, their behaviour and ultimate shear strength has been the subject of many researches to determine the influence of effective parameters. Several different modes of failure have been recognized in experimental studies. Due to the variability in the failure, the determination of shear capacity and the identification of failure mechanisms are very complicated. The existing methods for deep beams analyze and design consists of rational and semi-rational approaches, such as a sectional approach or a strut-and-tie model (STM). Few years ago, the market started to use fibre reinforced polymer (FRP) for structural reinforcement with other construction materials. FRP has several attractive features, such as low weight to strength ratio, non-corrosivity and high fatigue strength. Several resarchers studied the use of FRP sheets or plates bonded to concrete. Strengthening with adhesive-bonded FRPs has been developed as an effective method applicable to many types of concrete structures, such as columns, beams, slabs and walls, because FRP are non-corrosive, non-magnetic, and resistant to various types of chemicals, they are increasingly used for external reinforcement of existing concrete structures.

Islam et al. (2005) [1] researched on CFRP's contribution to the reinforcement of deep beams, it was recorded that the use of FRP sheet resulted in an increase in shear strength up to $40 \%$ for specimens which have 1.3 shear span/depth ratio.

Maaddawy and Sherif. (2009) [2] the structural response of RC deep beams with opening was studied. The shear strength of specimens depended largely on the degree of the interval of the ordinary load path. Asghari et al. (2013) [3], presented an experimental study on shear strength enhancement of lightweight deep beams externally reinforced with vertical CFRP sheets. The shear span/depth ratio was taken equal to 1, and the percentage of shear strength improving by strengthening was 30\%. Mohammad Panjehpour,1 Hwa Kian Chai,1 and Yen Lei Voo2.(2014) [4] They presented the effect of CFRP-strengthening on the deformation of $\mathrm{RC}$ strut in the design of deep beams .they reported that The value of transverse strain of ordinary RC struts remarkably grew faster than that of CFRP strengthened RC struts after the amount of loading was higher than approximately 40-60\% of ultimate shear strength of ordinary RC deep beams. M. Panjehpoura et al .(2014) [5] They proposes strut-and-tie model for CFRP-strengthened reinforced concrete deep beams. They found that that CFRP- 
strengthening increases the ultimate shear strength of deep beams from $19.60 \%$ to $30.02 \%$ with shear span-to-effective depth ratios of 0.75 to 2.00 , respectively. Rafid Saeed Atea.(2015) [6] studied the behavior of reinforced concrete deep beams strengthened and repaired with CFRP sheets in shear and examined how the number of layers and configuration of CFRP sheets affect the shear behavior .They found that the beams externally strengthened using CFRP sheets increased in ultimate loads. The increase in ultimate loads reached $(33 \%)$ and found also the decreased in deflection for SCC beams is attributed to the numbers, configurations and orientation of CFRP sheet of self-compacting concrete used in making these beams. Zhichao Zhang et al. (2004) [7] He investigated the shear behavior of deep beams with externally bonded CFRP shear reinforcement, he found that when a/d decreases, the shear strength of the beam has been found to increase. However, the shear contribution of CFRP laminates varies depending on the CFRP configuration. F Abed et al .(2012) [8] investigated the shear behavior of deep concrete beams reinforced with glass fiber reinforced polymer for flexure and without shear reinforcement. They found that that the stiffness of steel-reinforced concrete beams (the slope of the load-deflection curve ascending portion) is higher than that of beams reinforced with FRP bars due to the low axial stiffness of the FRP material. In addition, beams reinforced with FRP exhibited larger deformation at their ultimate failure load, after which a sudden failure occurred especially for beams having high shear capacity.

Khudair and Atea. (2015) [9] studied the shear behavior of self-compacting concrete (SCC) deep beams strengthened with CFRP sheets. They tested reinforced concrete (SCC) deep beams with shear span/depth ratio of 2 . The tested results show that the specimens strengthened by vertical CFRP sheets provided enhancement in ultimate loads reached $30 \%$. H.K. Lee et al .(2013) [10] studied the behavior and performance of RC T-section deep beams strengthened in shear with CFRP sheets . They found that the shear strengthening of CFRP sheets increases as the strengthening length increases with respect to ultimate load, initial stiffness, and ductility for all cases of $0^{\circ} / 0^{\circ}, 90^{\circ} / 90^{\circ}, 90^{\circ} / 0^{\circ}, 45^{\circ} / 135^{\circ}$ and $135^{\circ} / 45^{\circ}$ fiber direction combinations. In addition to the anchorage using U-wrapped CFRP sheets was shown to be very effective in increasing load carrying capacity, initial stiffness, and ductility, due to an anchorage effect. Mohammed Rasheed.(2016) [11] presented an experimental to discover the effect of the repair by vertical CFRP sheets on the shear strength of simply supported reinforced concrete deep beams. All beams have the same flexural reinforcement but Variable in vertical and longitudinal shear reinforcements ratio and Variable in shear span to depth ratios of $0.8,1$ and 1.2 ,he found that the enhancement magnitude of retrofit deep beam start from $8 \%$ to $161 \%$ of ultimate load of reference. Muhammad Afaq Javed et al. (2016) [12] they presented an experimental towards assessing the effectiveness of (CFRP) in upgrading the shear strength of deep beams. They found that big increase in overall load carrying capacities was observed with both CFRP sheets and web steel reinforcement. CFRP was found to be considerably effective in delaying the initial appearance of cracks of shear, consequently improving the serviceability limit state of deep beams. Dhahir, Mohammed Kareem .(2017) [13] proposes a Eurocode based Strut and Tie Model (STM) to evaluate the shear strength of FRP reinforced deep beams without web reinforcement. The proposed STM as well as those adopted by other codes were evaluated using a data base of 52 deep beams reinforced with various types of FRPs. The proposed STM has proved not only accurate but also conservative with an average predicted to experimental value of 0.96 and a standard deviation of 0.13 . While the STMs adopted by other codes have either overestimated or underestimated the shear strength. 


\section{METHODOLOGY}

The RC deep beams consisted of five groups: the first group without strengthening, the second, third, and fourth groups were strengthened with CFRP and GFRP, and the fifth group was pre-cracked then repaired with CFRP and GFRP. The first three groups contained three deep beams with shear span to effective depth ratios of 1.25, 1.50 and 1.75, and the last two groups was composed of two deep beams with shear span to effective depth ratios of 1.50 . CFRP and GFRP sheets are usually installed on two or three sides (U shape) or fully wrapped around the beam. In this study groups $2 \& 3$ we used $U$ shape and groups $4 \& 5$ we used strengthening on two sides only.

\subsection{Details of Deep Beams}

All the specimens had the same dimensions and reinforcement. The test specimens consisted of thirteen RC, simply supported deep beams divided into five groups. The specimens used in this research were normal strength concrete beams with a total depth of $450 \mathrm{~mm}$ and a width of $140 \mathrm{~mm}$. The length of all the specimens was $1900 \mathrm{~mm}$, and its clear spans were $1500 \mathrm{~mm}$. All the studied beams had $9 \Phi 18 \mathrm{~mm}$ with fy $=420 \mathrm{MPa}$ as the bottom longitudinal reinforcement. The top longitudinal reinforcement consisted of $2 \Phi 18 \mathrm{~mm}$ with fy $=420$ Mpa. The concrete dimensions, details of reinforcement and details of strengthening of beam specimens are shown in Figure (1).

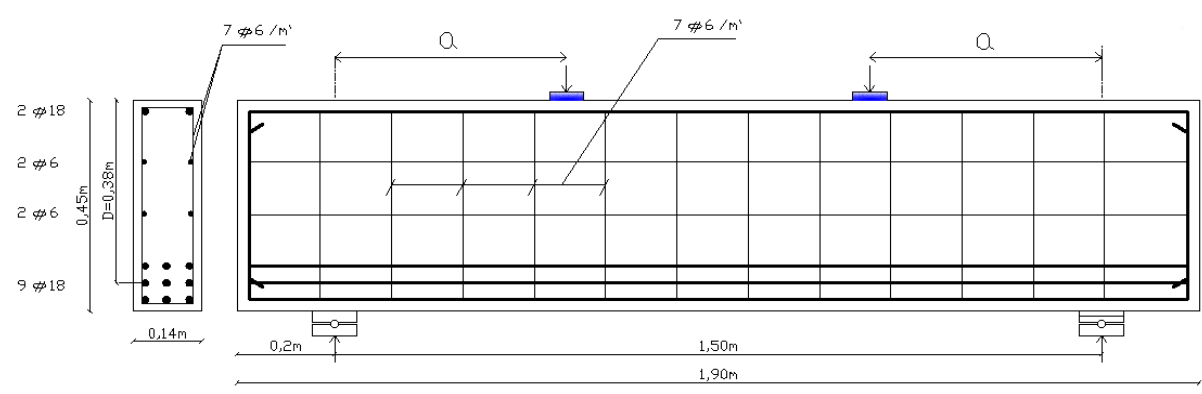

a. Concrete dimensions and details of reinforcement

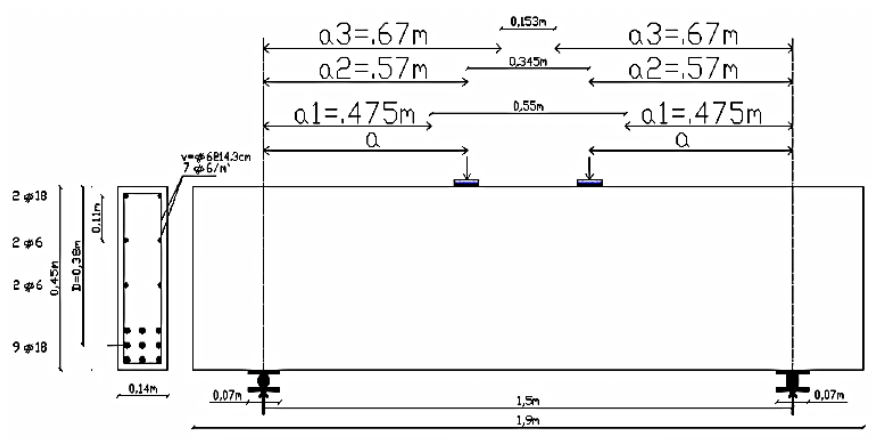

b. Dimensions of G1 


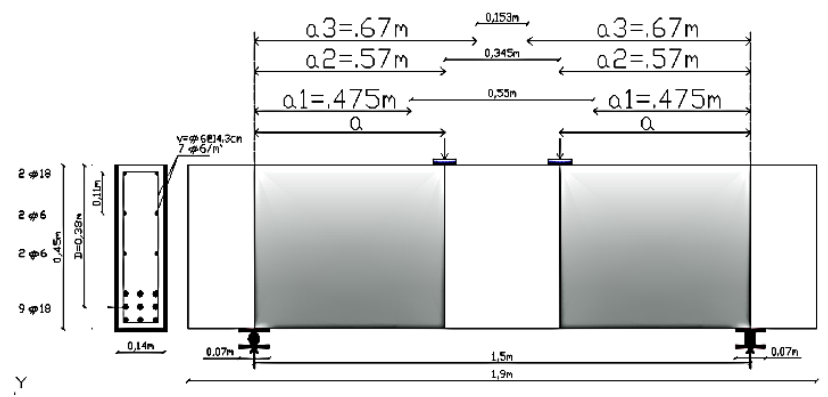

c. Dimensions and strengthening of G2

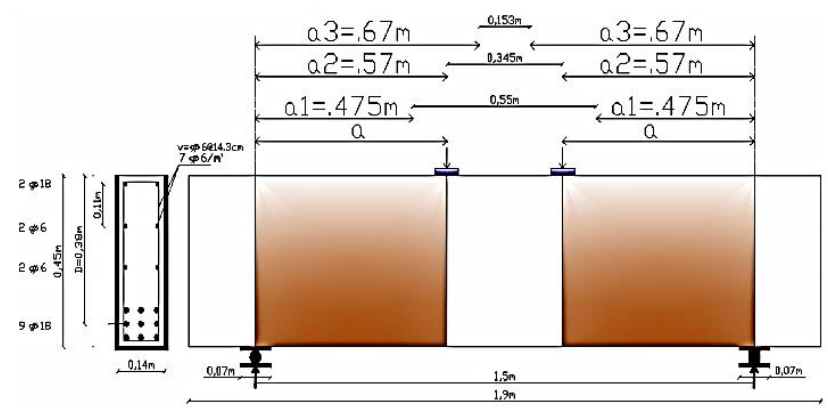

d. Dimensions and strengthening of G3

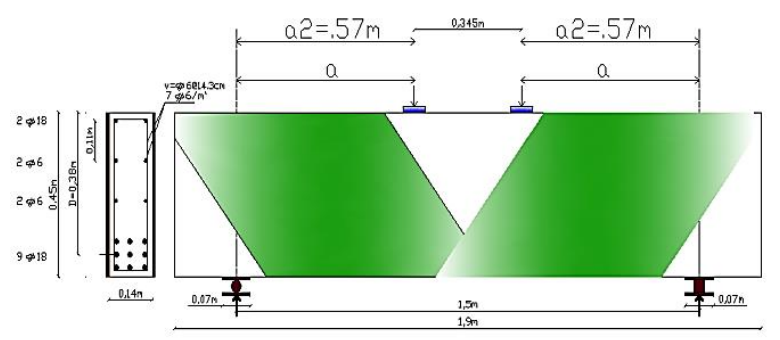

e. Dimensions and strengthening of G4

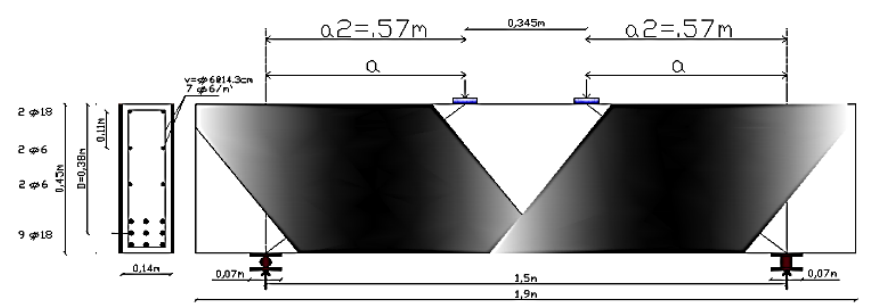

f. Dimensions and repairing of group G5

Figure 1 Concrete dimensions, details of reinforcement and details of strengthening of beam specimens 


\subsection{Materials and Methods}

One layer of unidirectional woven carbon fibre fabric with a thickness of $0.176 \mathrm{~mm} / \mathrm{ply}$ for GFRP and $0.35 \mathrm{~mm} / \mathrm{ply}$ for CFRP was wet-laid on the deep beams with a two-part epoxy resin. The direction of the fibre in the installed CFRP sheet was vertical.

Table 1.Typical properties of CFRP and GFRP sheets and epoxy

\begin{tabular}{|l|c|c|c|c|c|}
\hline \multicolumn{1}{|c|}{ Materials } & $\begin{array}{c}\text { Tensile strength } \\
(\mathbf{M P a})\end{array}$ & $\begin{array}{c}\text { Tensile modulus } \\
\text { of elasticity }(\mathbf{G P a})\end{array}$ & $\begin{array}{c}\text { Fibre density } \\
\left(\mathbf{g} / \mathbf{c m}^{\mathbf{3}}\right)\end{array}$ & $\begin{array}{c}\text { Bond strength } \\
(\mathbf{M P a})\end{array}$ & $\begin{array}{c}\text { Thickness } \\
(\mathbf{m m} / \mathbf{p l y})\end{array}$ \\
\hline CFRP SHEET & 3450 & 230 & 1.8 & - & 0.176 \\
\hline GFRP SHEET & 2300 & 76 & 2.56 & - & 0.35 \\
\hline Sikadur-330 & 30 & 4.5 & - & $>4$ & - \\
\hline
\end{tabular}

Table (1) lists the typical properties of the CFRP and GFRP sheets and the epoxy resin provided by the manufacturer. Both the CFRP sheet and epoxy resin were supplied by Sika Company with Sikadur-330 and Sikadur-31CF product data sheets. Strengthening with the CFRP and GFRP sheets was performed only on the surface of the beams between the load and support plate to cover the shear span of the deep beams. The CFRP strengthening was cured for at least two days. The deep beams were tested 28 days after casting.

\subsection{Test Procedures and Instruments}

The strains in the reinforcing steel were measured using six TML electrical strain gauges from Tokyo Sokki Kenkyujo Co., Ltd., type FLA-6-11-1L, with a gauge resistance of 350 ohms and a gauge length of $10 \mathrm{~mm}$. The strain gauges were attached to the steel using special epoxy adhesive after cleaning and smoothing the surface and then insulated from the wet concrete by means of a silicon coating. As shown in Figure (2).

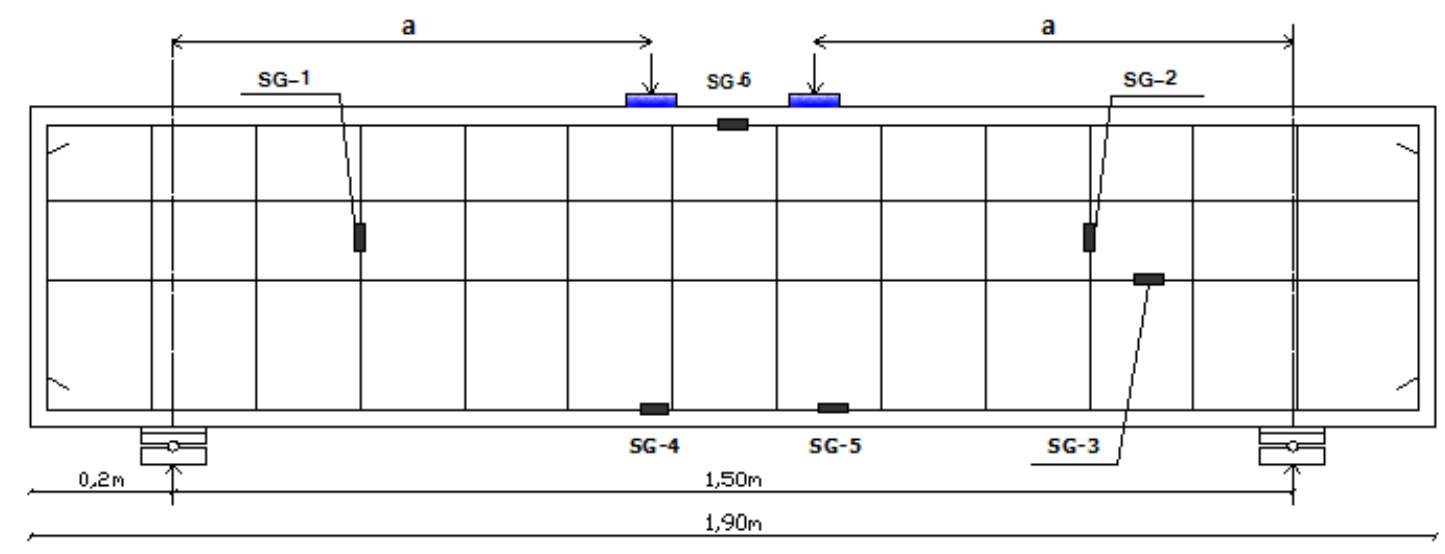

Figure 2 Locations of steel strain gauges

Tested beams were subjected to two concentrated loads and supported at two ends; each load was applied $200 \mathrm{~mm}$ from the end of the beam for the thirteen specimens.

All beams were loaded to failure using vertical hydraulic jack and a steel distribution beam with special bearing assemblies on the top face of the specimen. Linear variable differential transducers (LVDTs) were used to measure deflection through a computercontrolled data acquisition system, as shown in Figure (3). This system was used to record measurements at fixed time intervals. Measurements included load from the load cell, deflection from the LVDTs and strains at bottom bars, top bars, and stirrups from the electrical strain gauges. A diagonal LVDT on the face of the specimen perpendicular to the path of the shear crack was used to measure the concrete strain and width of cracks. The 
cracks at each incremental load were traced using a permanent marker, and photographs of the crack extent were taken. The test was finished when the beam was fractured, when extensive deformation was observed or when the load value was decreased.

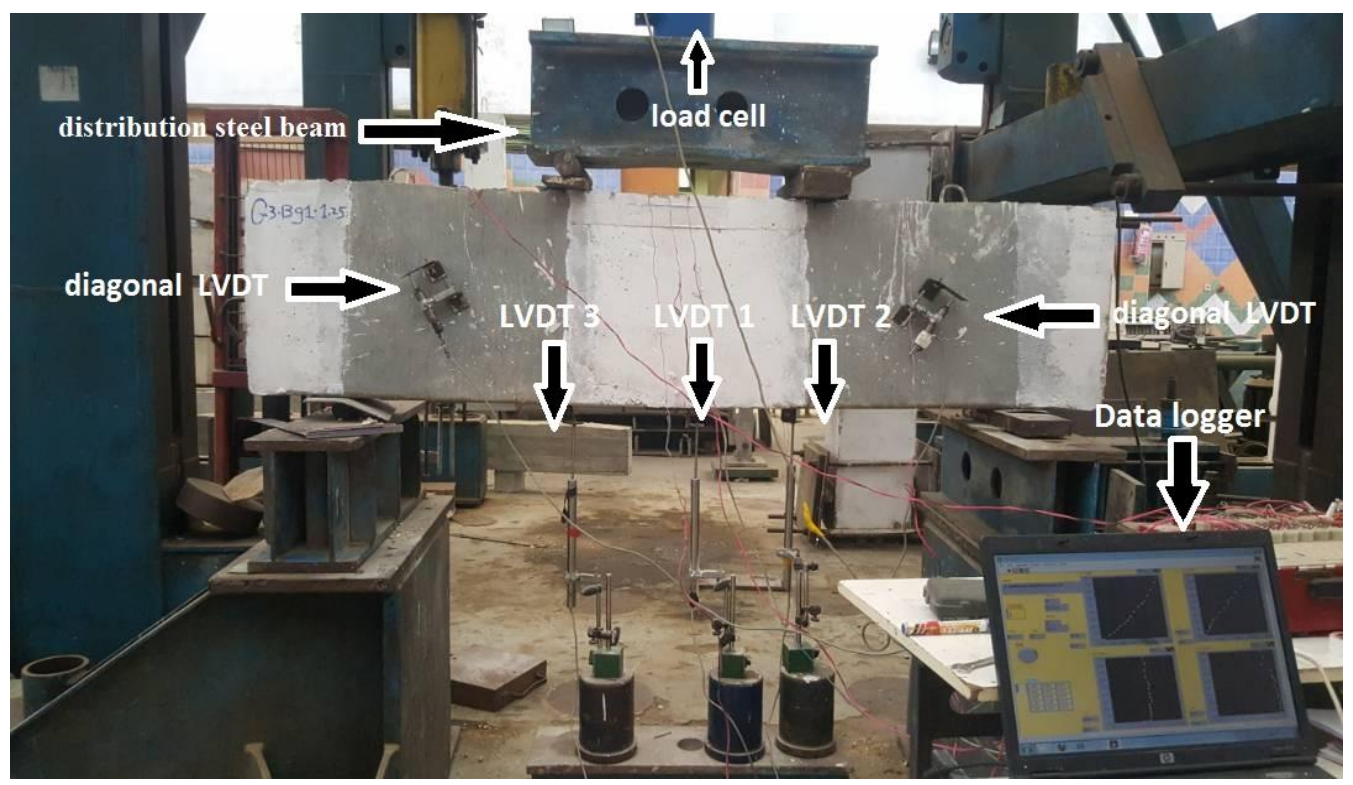

Figure 3 Test setup

\section{EXPERIMENTAL RESULTS}

The control and strengthened deep beams (first four groups) were tested under static loading until failure. In the fifth group, the deep beams were loaded until the first crack. Then, the beams were retrofitted by external CFRP and GFRP sheets and reloaded to failure again. The experimental applied load and the mid-span deflection were automatically recorded.

The crack patterns of the control, strengthened and retrofitted test beams are shown in Figure 4. The test results for all tested specimens are listed in Table 2.
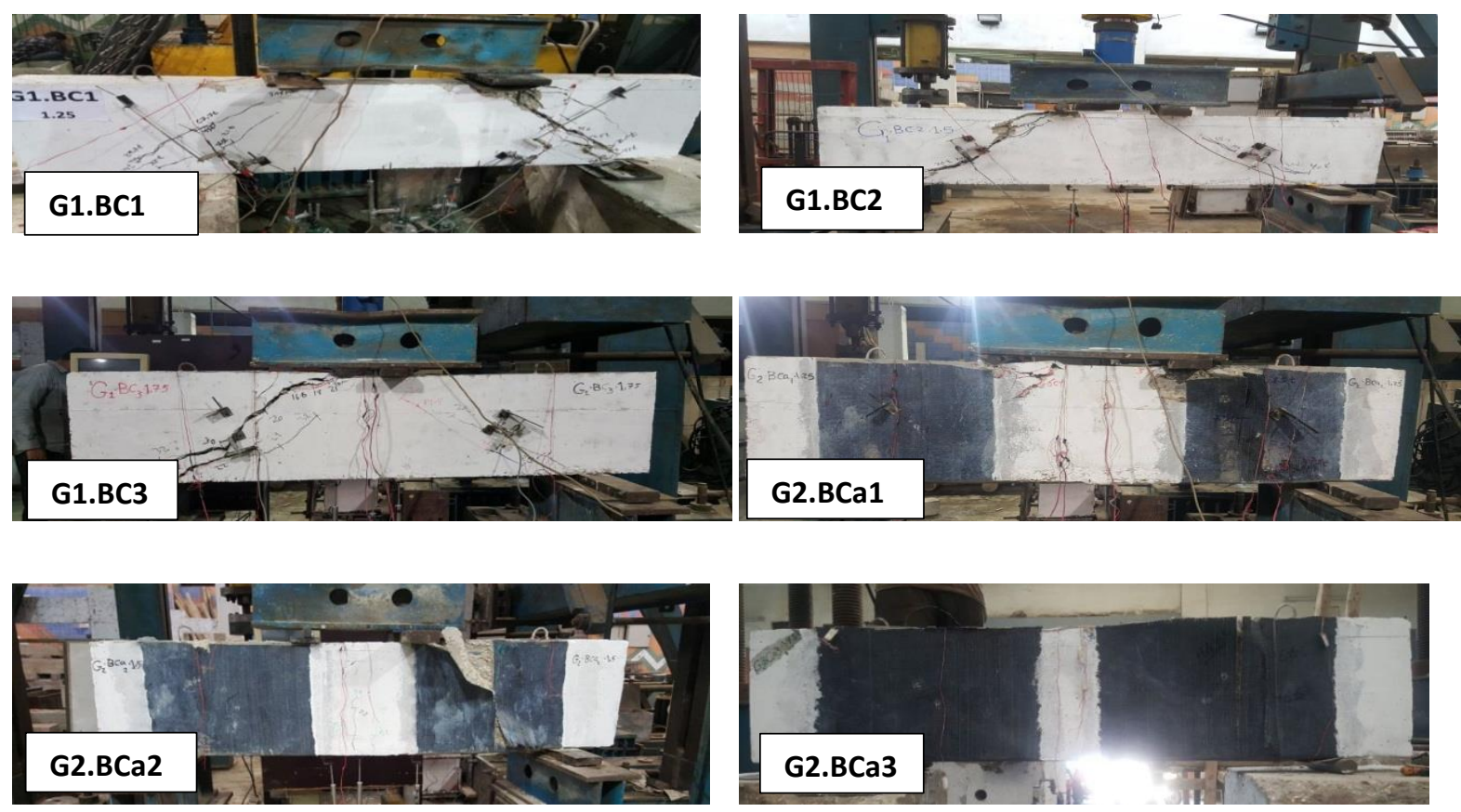

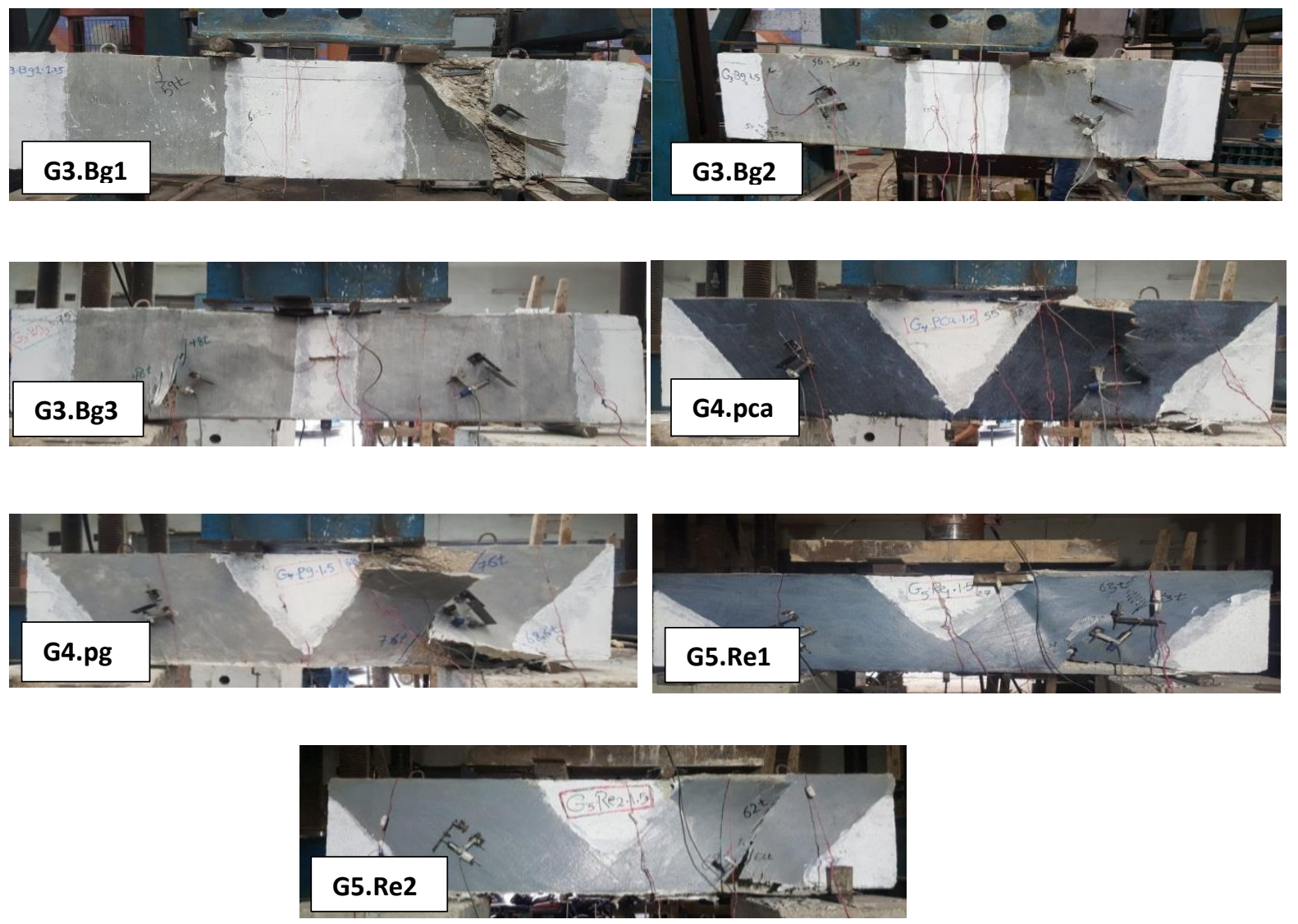

Figure 4 Crack patterns for tested deep beams

Table 2 Summary of test results for the tested beams

\begin{tabular}{|c|c|c|c|c|c|c|c|}
\hline $\begin{array}{l}\text { Group } \\
\text { No. }\end{array}$ & Specimen & $(\mathbf{a} / \mathbf{d})$ ratio & $\begin{array}{l}\text { Strengthened } \\
\text { with }\end{array}$ & $\begin{array}{c}\text { Failure } \\
\text { load } \\
(\mathbf{k N})\end{array}$ & $\begin{array}{c}\text { Shear } \\
\text { cracking } \\
\text { load } \\
(\mathbf{k N}) \\
\end{array}$ & $\begin{array}{c}\text { Max. } \\
\text { deflection } \\
(\mathbf{m m})\end{array}$ & $\begin{array}{c}\begin{array}{c}\text { Percentage of } \\
\text { increasing of } \\
\text { Failure Load } \\
\%\end{array} \\
\end{array}$ \\
\hline \multirow{3}{*}{ 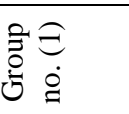 } & G1.BC1 & 1.25 & \multirow{3}{*}{$\begin{array}{l}\text { Reference beams } \\
\text { (No strengthening) }\end{array}$} & 471 & 241 & 7.2 & - \\
\hline & G1.BC2 & 1.5 & & 420.8 & 222 & 5.535 & - \\
\hline & G1.BC3 & 1.75 & & 325.5 & 136.9 & 5.5 & - \\
\hline \multirow{3}{*}{ 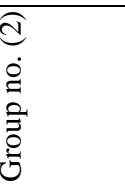 } & G2.BCa1 & 1.25 & \multirow{3}{*}{$\begin{array}{l}\text { full wrap from } \\
\text { load to support } \\
\text { with U-shaped } \\
\text { CFRP sheets }\end{array}$} & 751.1 & 402.3 & 6.5 & $59.4 \%$ \\
\hline & G2.BCa2 & 1.5 & & 682 & 348.9 & 6.5 & $62 \%$ \\
\hline & G2.BCa3 & 1.75 & & 568.2 & 307.6 & 6.6 & $74.6 \%$ \\
\hline \multirow{3}{*}{ 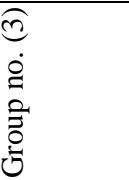 } & G3.BG1 & 1.25 & \multirow{3}{*}{$\begin{array}{l}\text { full wrap from } \\
\text { load to support } \\
\text { with U-shaped } \\
\text { GFRP sheets }\end{array}$} & 651.8 & 259.4 & 7.5 & $38.4 \%$ \\
\hline & G3.BG2 & 1.5 & & 563 & 231.1 & 6.697 & $33.8 \%$ \\
\hline & G3.BG3 & 1.75 & & 503.9 & 201.6 & 6.557 & $54.8 \%$ \\
\hline \multirow{2}{*}{ 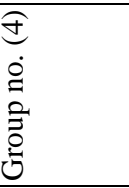 } & G4.PCa & 1.5 & \multirow{2}{*}{$\begin{array}{l}\text { Perpendi- } \\
\text { cular CFRP \& } \\
\text { GFRP sheets to } \\
\text { path of shear crack }\end{array}$} & 869.5 & 481.6 & 7.1 & $106.6 \%$ \\
\hline & G4.Pg & 1.5 & & 762.6 & 462.88 & 8.211 & $81.2 \%$ \\
\hline \multirow[b]{2}{*}{$\begin{array}{l}\dot{g} \\
\stackrel{0}{0} \\
\text { 苟 }\end{array}$} & G5.Re1 & 1.5 & \multirow{2}{*}{$\begin{array}{l}\text { Repaired pre- } \\
\text { cracked specimens } \\
\text { in perpendicular } \\
\text { direction on cracks } \\
\text { with CFRP \& } \\
\text { GFRP sheets }\end{array}$} & 680 & 140 & 7.5 & $61.6 \%$ \\
\hline & G5.Re2 & 1.5 & & 620.8 & 84 & 7.17 & $47.5 \%$ \\
\hline
\end{tabular}




\subsection{Crack Patterns}

Shear cracks initiated in the web in the direction from the loading point to the support. These diagonal cracks propagated upward to the loading point and downward to a location of support, and the width of diagonal shear cracks became wider with incremental loads.

Figure 4 shows the crack pattern for specimens. The crack patterns of the strengthened and repaired deep beams have different shapes from those of the control beams because of strengthening using CFRP and GFRP.

\subsection{Modes of Failure}

\subsubsection{Modes of Failure for Group G1}

The failure load of specimens decreased due to the increasing of shear span-to-depth ratio (a/d). The failure load and shear cracking load of specimens (G1.BC1, G1.BC2, and G1.BC3) are the reference for the strengthening specimens.

Increasing shear span-to-depth ratio $(\mathrm{a} / \mathrm{d})$ from 1.25 to 1.75 decreases the failure load by $31 \%$

The first crack load was about $51.2 \%, 52.8 \%$ and $42.1 \%$ of the failure load respectively.

\subsubsection{Modes of Failure for Group G2}

The failure load of each beam decreased due to the increasing of shear span-to-depth ratio $(\mathrm{a} / \mathrm{d})$, for specimens $(\mathrm{G} 2 . \mathrm{BCa} 1, \mathrm{G} 2 . \mathrm{BCa} 2, \mathrm{G} 2 . \mathrm{BCa} 3)$ the failure load was higher than control beam by about $59.4 \%, 62 \%$ and $74.6 \%$ respectively.

The first crack load was about $53.6 \%, 51.2 \%$ and $54.1 \%$ of the failure load respectively.

\subsubsection{Modes of Failure for Group G3}

The failure load of each beam decreased due to the increasing of shear span-to-depth ratio $(\mathrm{a} / \mathrm{d})$, for specimens $(\mathrm{G} 3 . \mathrm{Bg} 1, \mathrm{G} 3 . \mathrm{Bg} 2, \mathrm{G} 3 . \mathrm{Bg} 3)$ the failure load was higher than control beam by about $38.4 \%, 33.8 \%$ and $54.8 \%$ respectively.

The first crack load was about $39.8 \%, 41 \%$ and $40 \%$ of the failure load respectively.

\subsubsection{Modes of Failure for Group G4}

The failure load increased due to using CFRP in specimen G4.pca comparing with using GFRP in specimen G4.pg .The failure load also increased due to using CFRP\& GFRP sheets in specimens ( G4.pca, G4.pg ) comparing with control beam by about $106.6 \%$, and $81.2 \%$ respectively.

The first crack load was about $55.3 \%$ and $60.7 \%$ of the failure load respectively.

\subsubsection{Modes of Failure for Group G5}

The failure load increased due to using CFRP in specimen G5.Re1 comparing with using GFRP in specimen G5.Re2 .The failure load also increased due to using CFRP\&GFRP sheets in specimens ( G5.Re1 , G5.Re2 ) comparing with control beam by about $61.6 \%$, and $47.5 \%$ respectively.

The first crack load was about $20.5 \%$ and $13.5 \%$ of the failure load respectively.

\subsection{Load-Deflection Behaviour}

The load-deflection curves for the tested beams were approximately linear for a substantial portion of the loading stage, from zero-load to cracking failure of the concrete.Comparing the deflections of beams at the same load, the deflections were inversely proportional to the strengthening, as shown in Figure (5). 
Amr H. Zaher, Wael M. Montaser, Mahmoud M. Elsonbaty
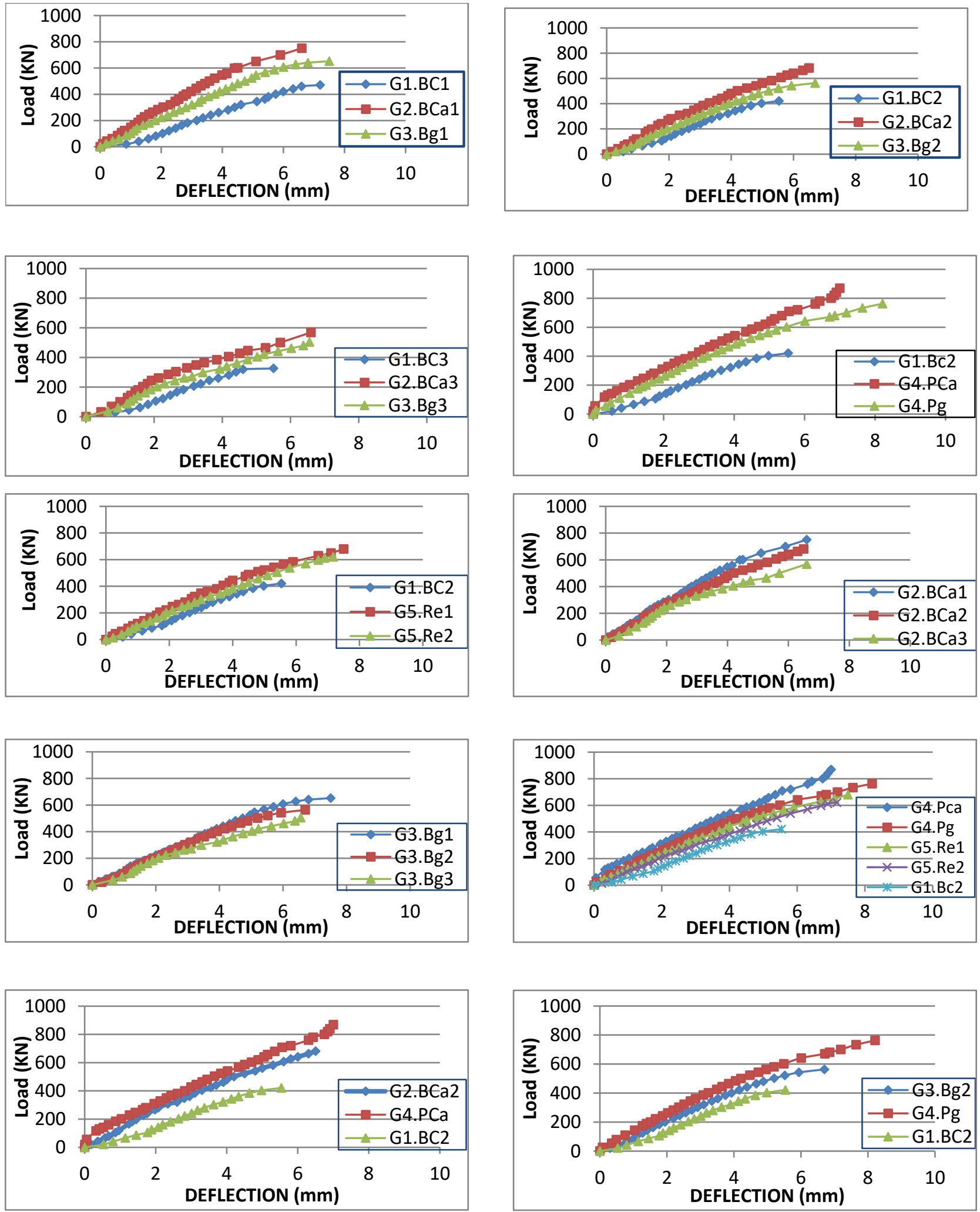

Figure 5 Load-deflection relationships for tested beams 
For beam specimens G3.Bg1 and G2B.Ca1, which were strengthened with U-shaped glass and carbon FRP sheets, the vertical deflections decreased by approximately $34.7 \%$ and $51 \%$, respectively, from $\mathrm{G1}$.BC1, which was not strengthened at the same load at a/d $=1.25$. For beam specimens $\mathrm{G} 3 . \mathrm{Bg} 2$ and $\mathrm{G} 2 \mathrm{BCa} 2$, which were strengthened with U-shaped glass and carbon FRP sheets, the vertical deflections decreased by approximately $21 \%$ and $40.2 \%$, respectively, from $\mathrm{G1}$.BC2, which was not strengthened at the same load at a/d $=1.5$. For beam specimens $\mathrm{G} 3 . \mathrm{Bg} 3$ and $\mathrm{G} 2 \mathrm{BCa} 3$, which were strengthened with U-shaped glass and carbon FRP sheets, the vertical deflections decreased by approximately $34.2 \%$ and $53.1 \%$, respectively, from $\mathrm{G1}$.BC3, which was not strengthened at the same load at $\mathrm{a} / \mathrm{d}=1.75$. For beam specimens G4.Pg and G4PCa, which were strengthened with diagonal glass and carbon FRP sheets, the vertical deflections decreased by approximately $39.6 \%$ and $46 \%$, respectively, from $\mathrm{G} 1 . \mathrm{BC} 2$, which was not strengthened at the same load at $\mathrm{a} / \mathrm{d}=1.5$. For beam specimens G5.Re2 and G5.Re1, which were repaired with diagonal glass and FRP sheets, the vertical deflections decreased by approximately 17.3 and $25.6 \%$, respectively, from G1.BC2, which was not repaired at the same load at a/d $=1.5$. For beam specimens G2.Bca2 and G2.Bca1, which were strengthened with U-shaped vertical carbon FRP sheets at different values of a/d $=1.5$ and 1.25 , the vertical deflections decreased by approximately $21.1 \%$ and $32.7 \%$, respectively, from G2.Bca3, which was strengthened with U-shaped carbon FRP sheets at a/d $=1.5$ at the same load. For beam specimens G3.Bg2 and G3.Bg1, which were strengthened with U-shaped vertical glass FRP sheets at different values of $\mathrm{a} / \mathrm{d}=1.5$ and 1.25 , the vertical deflections decreased by approximately $21.8 \%$ and $25.3 \%$, respectively, from G3.Bg3.1.75, which was strengthened with U-shaped glass FRP sheets at $\mathrm{a} / \mathrm{d}=1.5$ at the same load.

The deflections decreased due to strengthening because of increase beams stiffness

\subsection{Crack Widths}

Comparing the crack widths of beams at the same load, the crack width was inversely proportional to the strengthening, as shown in Figure (6).

For beam specimens G3.Bg1 and G2.BCa1, which were strengthened with U-shaped glass and carbon FRP sheets, the crack widths of beams decreased by approximately $47.5 \%$ and $78 \%$, respectively, from G1.BC1, which was not strengthened at the same load at $\mathrm{a} / \mathrm{d}=1.25$. For beam specimens $\mathrm{G} 3 . \mathrm{Bg} 2$ and $\mathrm{G} 2 . \mathrm{BCa} 2$, which were strengthened with U-shaped glass and carbon FRP sheets, the crack widths of beams decreased by approximately $42.8 \%$ and $63.3 \%$, respectively, from G1.BC2, which was not strengthened at the same load at $\mathrm{a} / \mathrm{d}=1.5$. For beam specimens $\mathrm{G} 3 . \mathrm{Bg} 3$ and $\mathrm{G} 2 . \mathrm{BCa} 3$, which were strengthened with U-shaped glass and carbon FRP sheets, the crack widths of beams decreased by approximately $51 \%$ and $77 \%$, respectively, from $\mathrm{G1}$.BC3, which was not strengthened at the same load at $\mathrm{a} / \mathrm{d}=1.75$. For beam specimens G4.Pg and G4.PCa, which were strengthened with diagonal glass and carbon FRP sheets, the crack widths of beams decreased by approximately $68.3 \%$ and $93.6 \%$, respectively, from G1.BC2, which was not strengthened at the same load at a/d $=1.5$. For beam specimens G5.Re2 and G5.Re1, which were repaired diagonally with glass and carbon FRP sheets, the crack widths of beams decreased by approximately $44.3 \%$ and $54.9 \%$, respectively, from G1.BC2, which was not repaired with FRP at the same load at a/d $=1.5$. For beam specimens G2.Bca2 and G2.Bca1, which were strengthened with U-shaped vertical carbon FRP sheets at different values of $\mathrm{a} / \mathrm{d}=1.5$ and 1.25 , the crack widths of beams decreased by approximately $31 \%$ and $83.4 \%$, respectively, from G2.Bca3, which was strengthened with U-shaped carbon FRP sheets at a/d $=1.75$ at the same load. For beam specimens G3.Bg2 and G3.Bg1, which were strengthened with U-shaped vertical glass FRP sheets at different values of $\mathrm{a} / \mathrm{d}=1.5$ and 1.25 , the crack widths of beams decreased by approximately $40.7 \%$ and $88.1 \%$, respectively, from $\mathrm{G} 2 . \mathrm{Bg} 3$, which was strengthened with Ushaped glass FRP sheets at a/d $=1.75$ at the same load. 
Amr H. Zaher, Wael M. Montaser, Mahmoud M. Elsonbaty
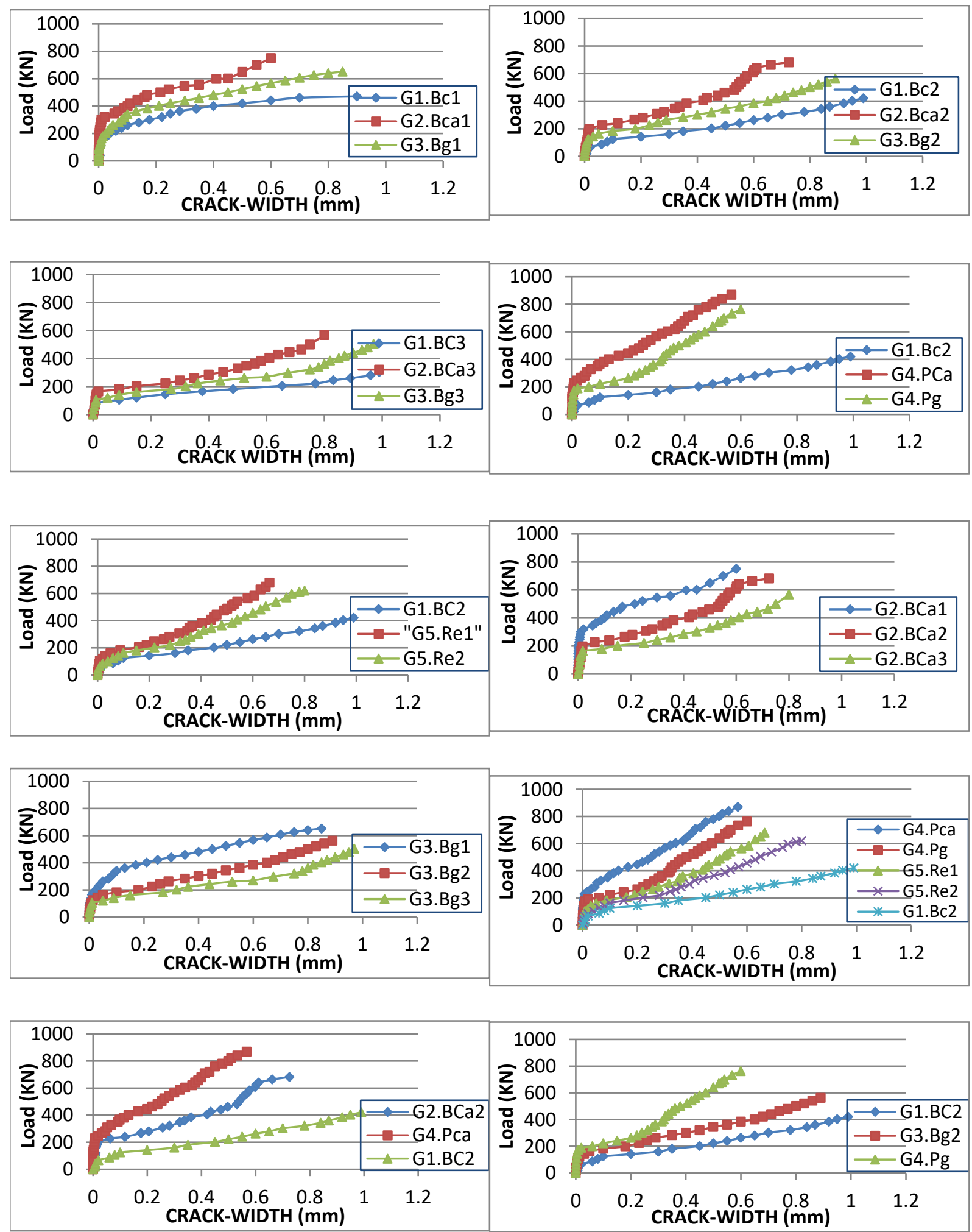

Figure 6 Load- crack width relationships for tested beams 


\subsection{Steel Strain}

\subsubsection{Main Steel Strain}
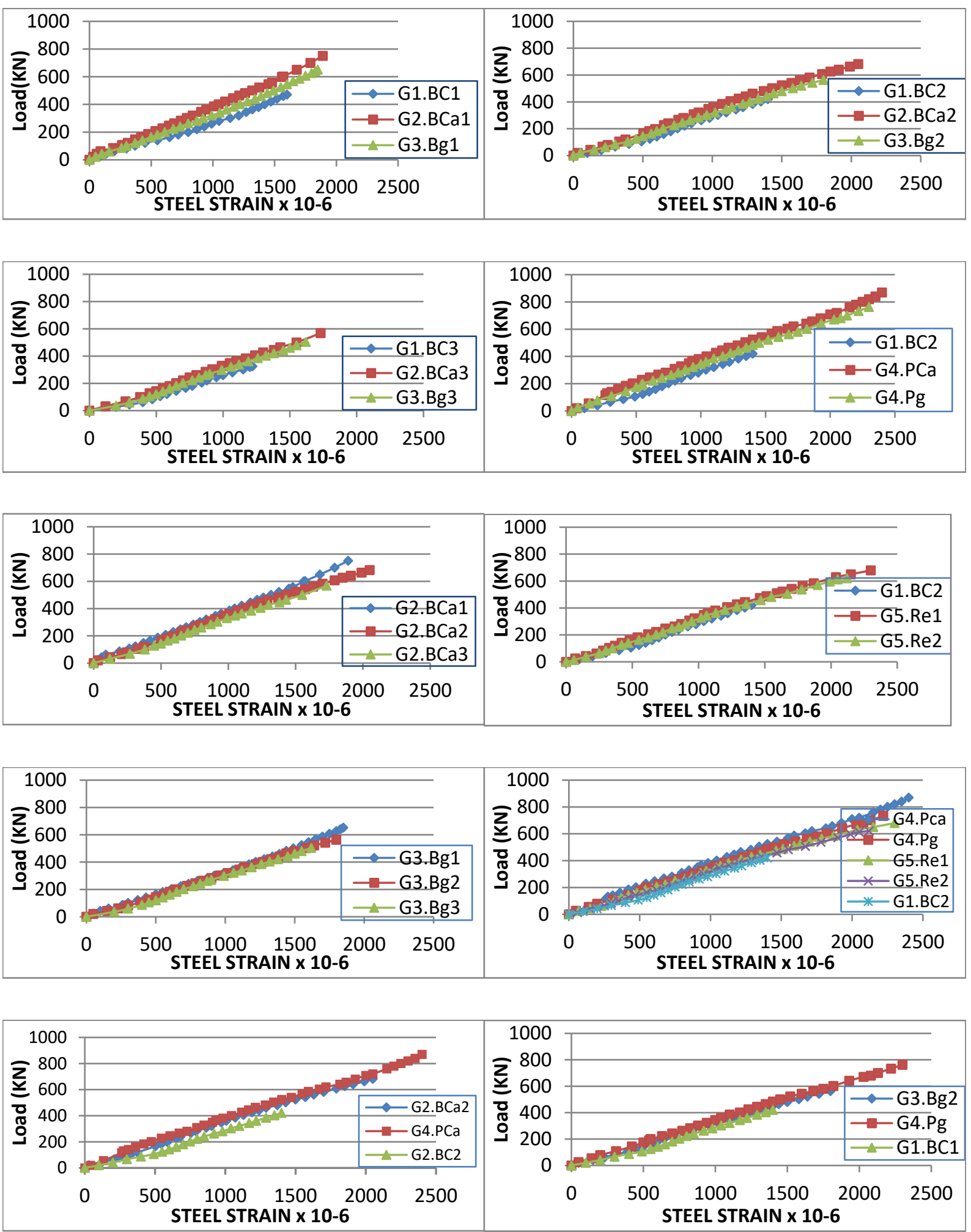

Figure 7 Load - main steel strain relationships for tested beams

Comparing the longitudinal steel strains of beams is shown in Figure (7). For beam specimens $\mathrm{G} 3 \mathrm{Bg} 1$ and $\mathrm{G} 2 \mathrm{BCa} 1$, which were strengthened with U-shaped glass and carbon 
FRP sheets, the longitudinal steel strains decreased by approximately $19.3 \%$ and $30.7 \%$, respectively, from $\mathrm{G1}$.BC1, which was not strengthened at the same load at $\mathrm{a} / \mathrm{d}=1.25$. For beam specimens $\mathrm{G} 3 . \mathrm{Bg} 2$ and $\mathrm{G} 2 . \mathrm{BCa} 2$, which were strengthened with U-shaped glass and carbon FRP sheets, the longitudinal steel strains decreased by approximately $7.7 \%$ and $16.8 \%$, respectively, from G1.BC2, which was not strengthened at the same load at $\mathrm{a} / \mathrm{d}=1.5$. For beam specimens G3.Bg3 and G2.BCa3, which were strengthened with U-shaped glass and carbon FRP sheets, the longitudinal steel strains decreased by approximately $13 \%$ and $20 \%$, respectively, from G1.BC3, which was not strengthened at the same load at a/d $=1.75$. For beam specimens G4.Pg and G4.PCa1, which were strengthened diagonally with glass and carbon FRP sheets, longitudinal steel strains decreased by approximately $15.4 \%$ and $23.4 \%$, respectively, from G1.BC2, which was not strengthened at the same load at a/d $=1.5$. For beam specimens G5.Re2 and G5.Re1, which were repaired diagonally with glass and carbon FRP sheets, the longitudinal steel strains decreased by approximately $8.7 \%$ and $10.6 \%$, respectively, from G1.BC2, which was not repaired at the same load at a/d $=1.5$. For beam specimens G2.Bca2 and G2.Bca1, which were strengthened with U-shaped vertical carbon FRP sheets at different values of $\mathrm{a} / \mathrm{d}=1.5$ and 1.25 , the longitudinal steel strains decreased by approximately $6 \%$ and $14 \%$, respectively, from G2.Bca3, which was strengthened with Ushaped carbon FRP sheets at a/d =1.75 at the same load. For beam specimens G3.Bg2 and G3.Bg1, which were strengthened with U-shaped vertical glass FRP sheets at different values of $\mathrm{a} / \mathrm{d}=1.5$ and 1.25 , the longitudinal steel strains decreased by approximately $3 \%$ and $7 \%$, respectively, from G3.Bg3, which was strengthened with U-shaped glass FRP sheets at a/d $=1.75$ at the same load.

\subsubsection{Vertical Stirrup Steel Strain}

Comparisons of the steel strains in the vertical stirrup steels of beams are shown in Figure (8).

For beam specimens G3Bg1 and G2BCa1, which were strengthened with U-shaped glass and carbon FRP sheets, the steel strains in the vertical stirrups decreased by approximately $62.7 \%$ and $79.2 \%$, respectively, from G1.BC1, which was not strengthened at the same load at $\mathrm{a} / \mathrm{d}=1.25$. For beam specimens $\mathrm{G} 3 . \mathrm{Bg} 2$ and $\mathrm{G} 2 . \mathrm{BCa} 2$, which were strengthened with $\mathrm{U}$ shaped glass and carbon FRP sheets, the steel strains in the vertical stirrups decreased by approximately $45 \%$ and $63.3 \%$, respectively, from G1.BC2, which was not strengthened at the same load at $\mathrm{a} / \mathrm{d}=1.5$. For beam specimens $\mathrm{G} 3 . \mathrm{Bg} 3$ and $\mathrm{G} 2 . \mathrm{BCa} 3$, which were strengthened with U-shaped glass and carbon FRP sheets, the steel strains in the vertical stirrups decreased by approximately $56 \%$ and $84.8 \%$, respectively, from G1.BC3, which was not strengthened at the same load at $\mathrm{a} / \mathrm{d}=1.75$. For beam specimens G4.Pg and G4.PCa1, which were strengthened diagonally with glass and carbon FRP sheets, steel strains in the vertical stirrups decreased by approximately $81.7 \%$ and $85.8 \%$, respectively, from G1.BC2, which was not strengthened at the same load at a/d =1.5. For beam specimens G5.Re 2 and G5.Re1, which were repaired diagonally with glass and carbon FRP sheets, the steel strains in the vertical stirrups decreased by approximately $39.7 \%$ and $60.1 \%$, respectively, from G1.BC2, which was not repaired at the same load at a/d $=1.5$. For beam specimens $\mathrm{G} 2$. Bca2 and G2.Bca1, which were strengthened with U-shaped vertical carbon FRP sheets at different values of $\mathrm{a} / \mathrm{d}=1.5$ and 1.25 , the steel strains in the vertical stirrups decreased by approximately $44.9 \%$ and $67.7 \%$, respectively, from G2.Bca3, which was strengthened with U-shaped carbon FRP sheets at a/d =1.75 at the same load. For beam specimens G3.Bg2 and G3.Bg1, which were strengthened with U-shaped vertical glass FRP sheets at different values of $\mathrm{a} / \mathrm{d}=1.5$ and 1.25 , the steel strains in the vertical stirrups decreased by approximately $12.75 \%$ and $35.5 \%$, respectively, from $\mathrm{G} 3 . \mathrm{Bg} 3$, which was strengthened with U-shaped glass FRP sheets at $\mathrm{a} / \mathrm{d}=1.75$ at the same load. 

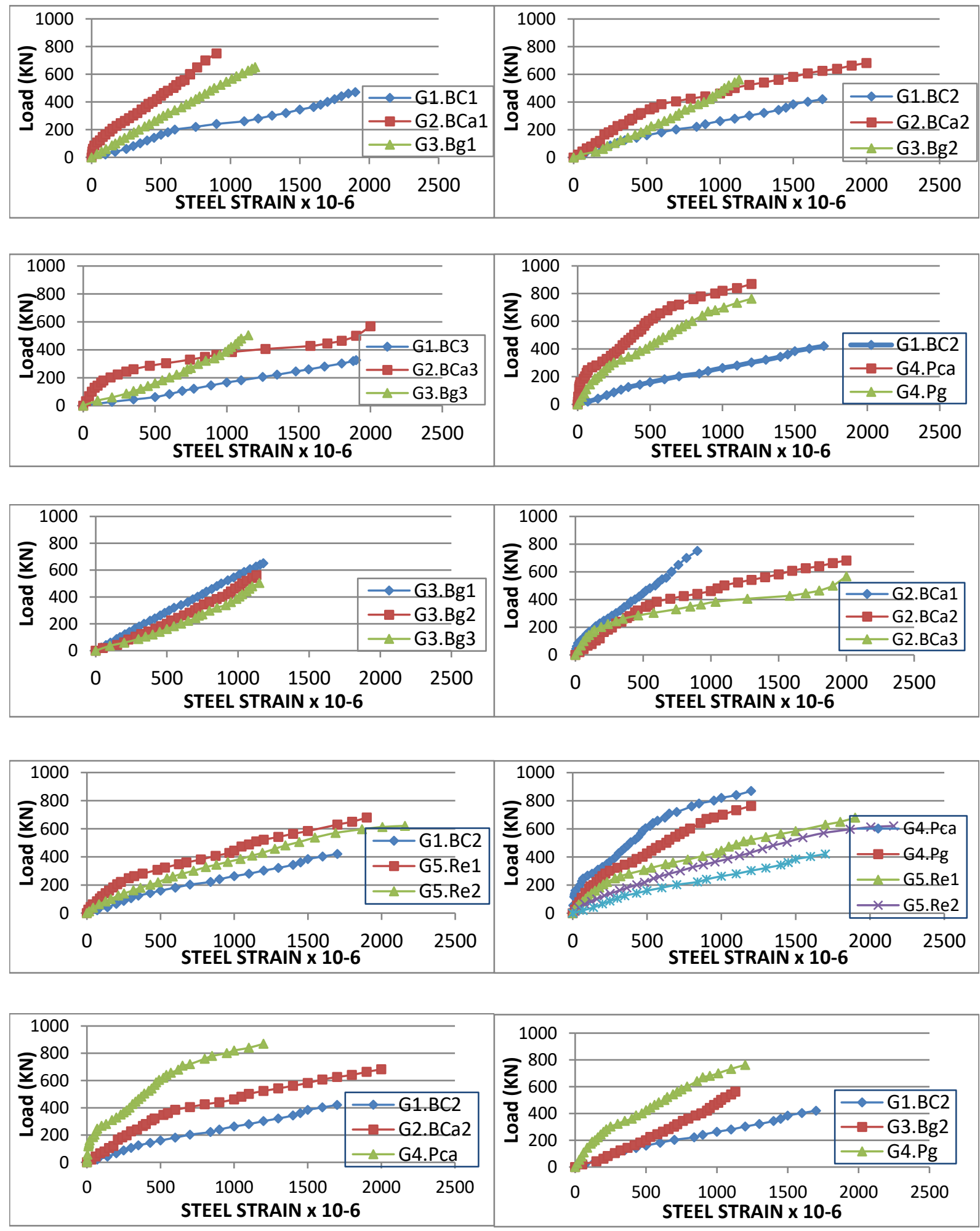

Figure 8 Load -vertical stirrups strain relationships for tested beams 


\subsubsection{Horizontal Stirrup Steel Strain}

Comparisons of the steel strains in the horizontal stirrups of beams are shown in Figure (9).
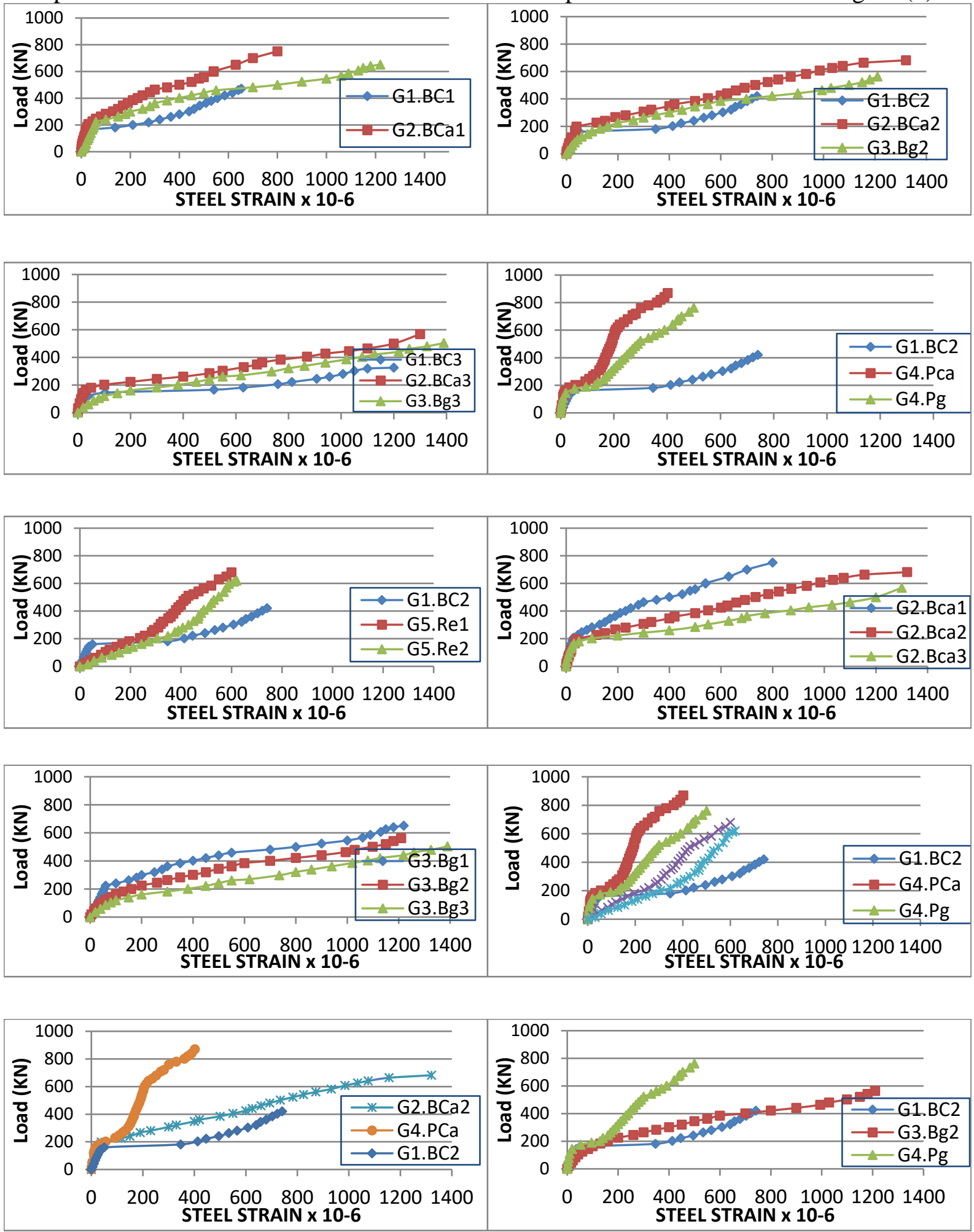

Figure 9 Load- horizontal stirrups relationships for tested beams 
For beam specimens G3Bg1 and G2BCa1, which were strengthened with U-shaped glass and carbon FRP sheets, the steel strains in the horizontal stirrups decreased by approximately $54.5 \%$ and $77.3 \%$, respectively, from G1.BC1, which was not strengthened at the same load at $\mathrm{a} / \mathrm{d}=1.25$. For beam specimens $\mathrm{G} 3 . \mathrm{Bg} 2$ and $\mathrm{G} 2 . \mathrm{BCa} 2$, which were strengthened with Ushaped glass and carbon FRP sheets, the steel strains in the horizontal stirrups decreased by approximately $34.2 \%$ and $50.7 \%$, respectively, from G1.BC2, which was not strengthened at the same load at $\mathrm{a} / \mathrm{d}=1.5$. For beam specimens $\mathrm{G} 3 . \mathrm{Bg} 3$ and $\mathrm{G} 2 . \mathrm{BCa} 3$, which were strengthened with U-shaped glass and carbon FRP sheets, the steel strains in the horizontal stirrups decreased by approximately $30 \%$ and $47.6 \%$, respectively, from G1.BC3, which was not strengthened at the same load at $\mathrm{a} / \mathrm{d}=1.75$. For beam specimens G4.Pg and G4.PCa1, which were strengthened diagonally with glass and carbon FRP sheets, the steel strains in the horizontal stirrups decreased by approximately $70.4 \%$ and $78.4 \%$, respectively, from G1.BC2, which was not strengthened at the same load at $\mathrm{a} / \mathrm{d}=1.5$. For beam specimens G5.Re 2 and G5.Re1, which were repaired diagonally with glass and carbon FRP sheets, the steel strains in the horizontal stirrups decreased by approximately $29.3 \%$ and $47.4 \%$, respectively, from G1.BC2, which was not repaired at the same load at a/d $=1.5$. For beam specimens $\mathrm{G} 2$.Bca2 and G2.Bca1, which were strengthened with U-shaped vertical carbon FRP sheets at different $\mathrm{a} / \mathrm{d}=1.5$ and 1.25 , the steel strains in the horizontal stirrups decreased by approximately $36.8 \%$ and $75.9 \%$, respectively, from G2.Bca3, which was strengthened with U-shaped carbon FRP sheets at a/d $=1.75$ at the same load. For beam specimens $\mathrm{G} 3 . \mathrm{Bg} 2$ and $\mathrm{G} 3 . \mathrm{Bg} 1$, which were strengthened with U-shaped vertical glass FRP sheets at different $\mathrm{a} / \mathrm{d}=1.5$ and 1.25 , the steel strains in the horizontal stirrups decreased by approximately $35.2 \%$ and $63 \%$, respectively, from G3.Bg3, which was strengthened with U-shaped glass FRP sheets at a/d $=1.75$ at the same load.

\section{ANALYTICAL STUDY}

\subsection{Shear Strengthening}

The nominal shear strength of an FRP-strengthened concrete beam can be determined by adding the shear resistance contribution of the FRP (Vf) to the steel stirrup contribution (Vs) and the concrete shear resistance $(\mathrm{Vc})$ according to:

$$
V=V_{\mathrm{c}}+V_{\mathrm{s}}+V_{\mathrm{f}}
$$

where Vc and Vs can be determined from design standards, such as ACI 318-08.

The shear contributions of the FRP shear reinforcement were computed with three existing design guidelines (ACI, BCS and EURO). Figure (10) shows the methods of strengthening concrete members for shear resistance; Figure (11) shows the definition of the variables required for calculating the shear strength of FRP composites; and Table 3 and Figure (12) show the comparison between predicted and experimental shear strength. Finally, Figure (13) shows the comparison of shear contributions between our test results and predictions from design guidelines.

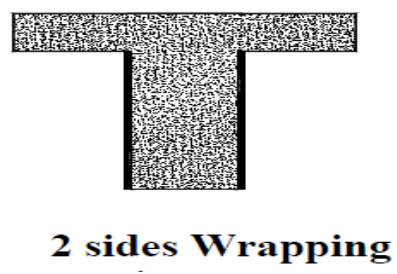

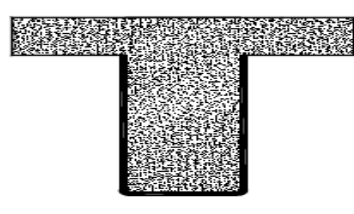

3 side Wrapping

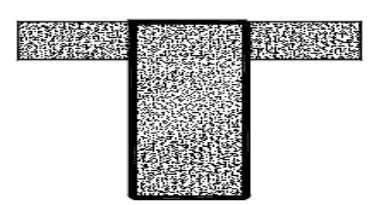

Full Wrapping

Figure 10 Methods of strengthening concrete members for shear resistance 

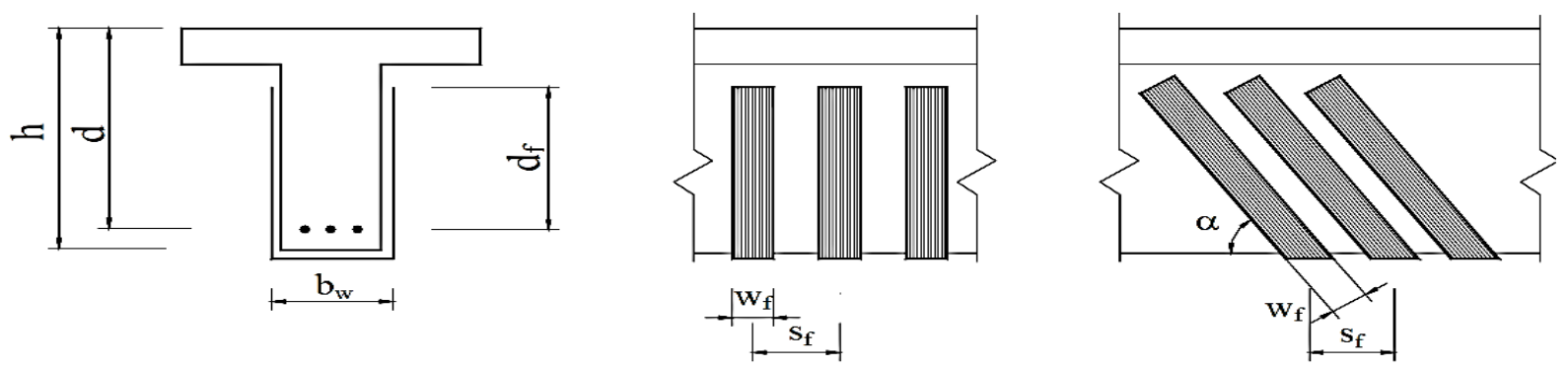

Figure 11 Definitions of variables required for calculating shear strength of FRP composites

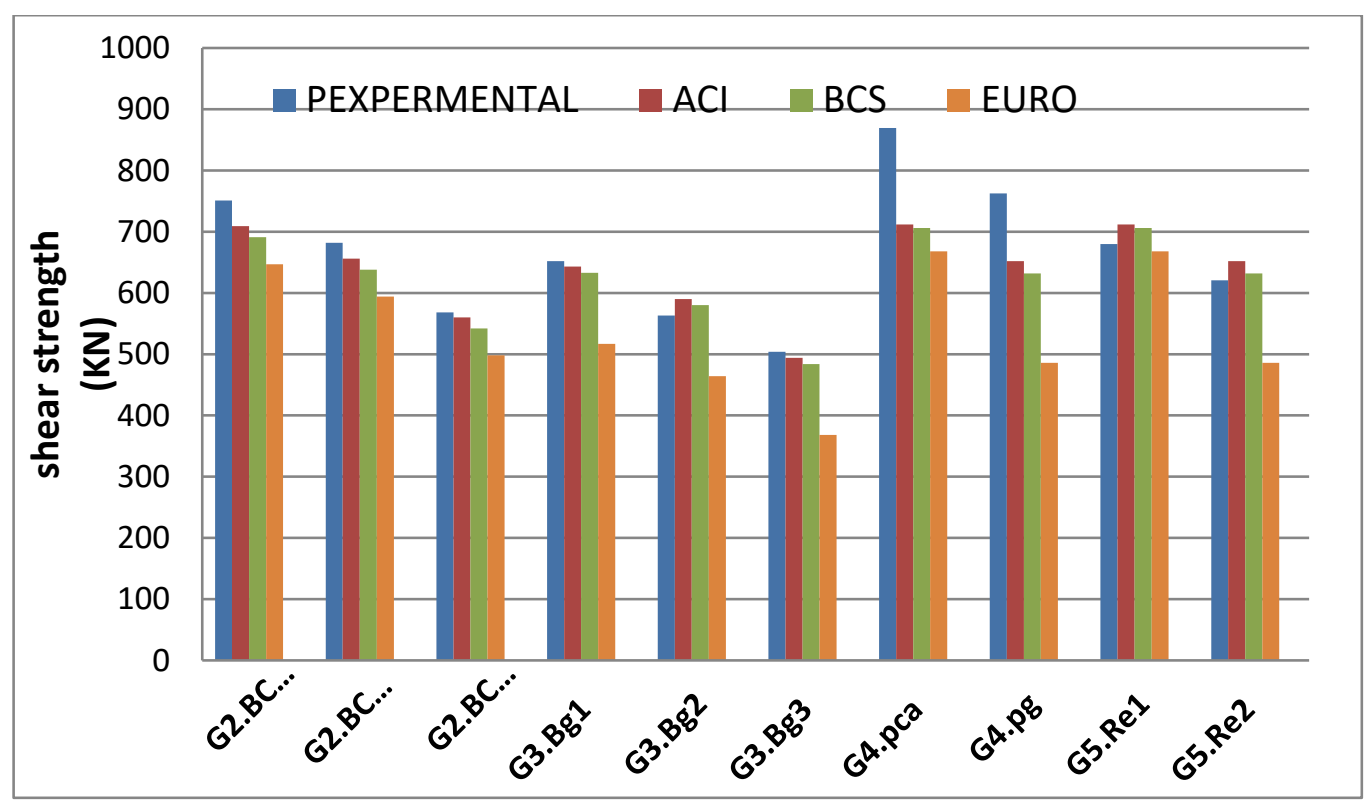

Figure 12 Comparison between predicted and experimental shear strengths

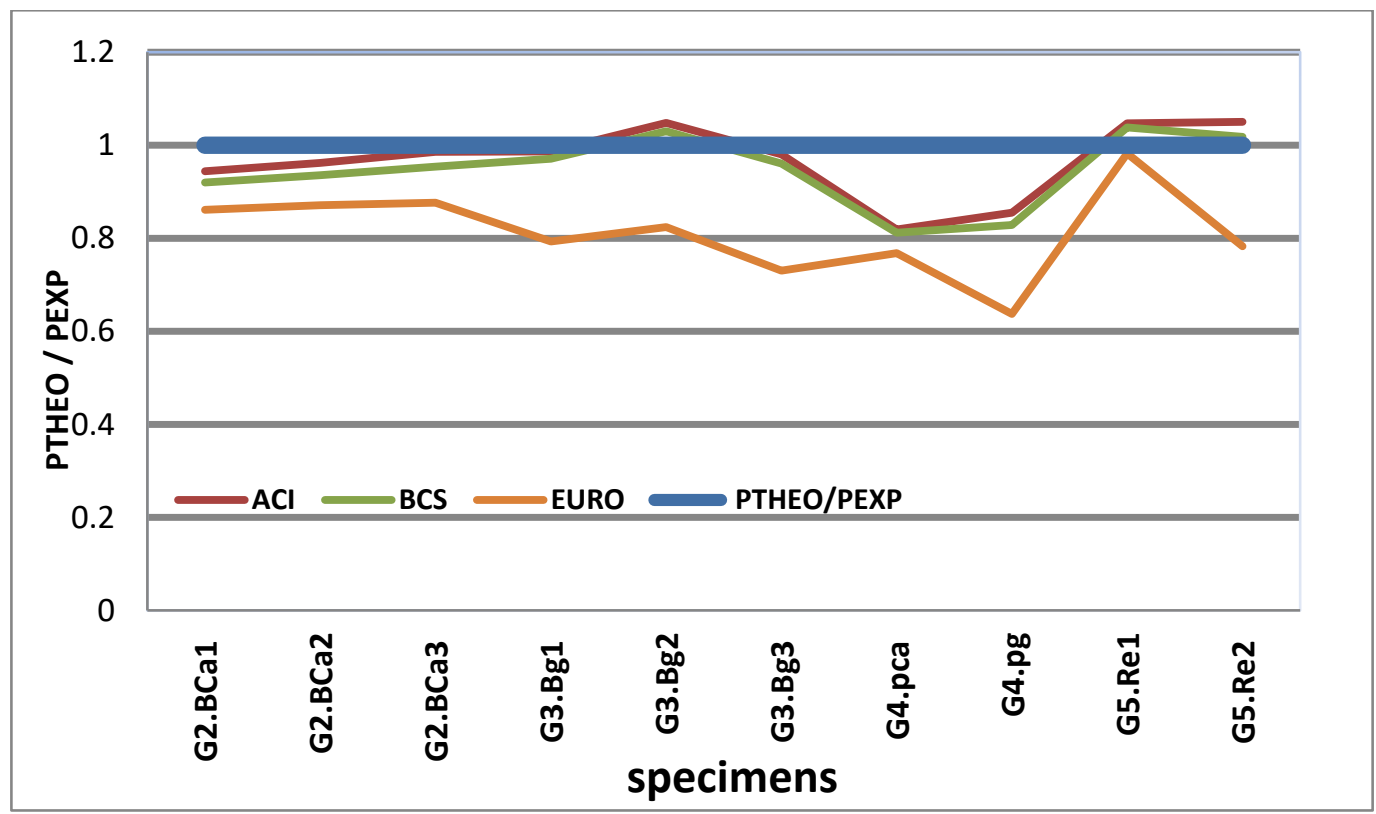

Figure 13 Comparison of shear contributions between our test results and predictions from codes equations 
Table 3. Comparison between predicted and experimental shear strengths

\begin{tabular}{|c|c|c|c|c|c|c|c|}
\hline \multirow{2}{*}{ Specimen } & \multirow{2}{*}{ P $_{\text {EXP }}$} & \multicolumn{2}{|c|}{ ACI } & \multicolumn{2}{c|}{ BSC } & \multicolumn{2}{c|}{ EURO } \\
\cline { 3 - 8 } & & $\mathbf{P}_{\text {Theo }}$ & $\begin{array}{c}\mathbf{P}_{\text {THEO/ }} \\
\mathbf{P}_{\text {EXP }}\end{array}$ & P $_{\text {TheO }}$ & $\begin{array}{c}\mathbf{P}_{\text {THEO/ }} \\
\mathbf{P}_{\text {EXP }}\end{array}$ & P $_{\text {Theo }}$ & P $_{\text {TheO// } / \text { EXP }}$ \\
\hline G2.BCa1.1.25 & 751.1 & 709 & 0.94 & 691 & 0.92 & 647 & 0.86 \\
\hline G2.BCa2.1.5 & 682 & 656 & 0.96 & 638 & 0.94 & 594 & 0.87 \\
\hline G2.BCa3.1.75 & 568.2 & 560 & 0.99 & 542 & 0.95 & 498 & 0.88 \\
\hline G3.Bg1.1.25 & 651.8 & 643 & 0.99 & 633 & 0.97 & 517 & 0.79 \\
\hline G3.Bg2.1.5 & 563 & 590 & 1.05 & 580 & 1.03 & 464 & 0.82 \\
\hline G3.Bg3.1.75 & 503.9 & 494 & 0.98 & 484 & 0.96 & 368 & 0.73 \\
\hline G4.pca.1.5 & 869.5 & 712 & 0.82 & 706 & 0.81 & 668 & 0.77 \\
\hline G4.pg.1.5 & 762.6 & 652 & 0.86 & 632 & 0.83 & 486 & 0.64 \\
\hline G5.Re1.1.5 & 680 & 712 & 1.05 & 706 & 1.04 & 668 & 0.98 \\
\hline G5.Re2.1.5 & 620.8 & 652 & 1.05 & 632 & 1.02 & 486 & 0.78 \\
\hline
\end{tabular}

\subsubsection{American Concrete Institute (ACI)}

The shear contribution of the FRP shear reinforcement can be determined by:

$$
V_{f}=\left(A_{f} E_{f} \varepsilon_{f}(\sin \beta+\cos \beta) d\right) /\left(s_{f}\right)
$$

where $\beta$ is the inclination angle of the FRP, $s_{f}$ is the width of the FRP, $d=d_{f}$ is the depth to the shear reinforcement and $\mathrm{A}_{\mathrm{f}}$ is the total FRP area, which is given by:

$$
A_{f}=2 n t_{f} S_{f}
$$

where $n$ is the number of FRP sheets, $t_{f}$ is the thickness of the FRP, $E_{f}$ is the FRP modulus of elasticity and $\varepsilon_{\mathrm{fe}}$ is the effective strain, which is the maximum strain that can be achieved in the FRP reinforcement system. The maximum strain used for design should be limited to $0.4 \%$ for applications that are completely wrapped with FRP.

$$
\varepsilon_{\mathrm{fe}}=0.004 \leq 0.75 \varepsilon_{\mathrm{fu}}
$$

For U-wrapped or bonded face ply systems, the FRP does not close the entire section. Therefore, bond stresses should be analysed to determine the usage and effective strain level that can be achieved. The effective strain for U-wrapped or face plies can be calculated using the strain reduction coefficient $\mathrm{K}_{\mathrm{V}}$ :

$$
\varepsilon_{\mathrm{fe}}=K_{\mathrm{v}} \varepsilon_{\mathrm{fu}} \leq 0.004
$$

This factor depends on the strengthening scheme, which depends on the concrete strength, the type of wrapping scheme used and the stiffness of the sheets. The strain reduction factor is given by:

$$
K_{\mathrm{v}}=k_{1} k_{2} L_{\mathrm{e}} / 11900 \varepsilon_{\mathrm{fu}} \leq 0.75
$$

where the effective length of the FRP sheet is given by:

$$
L_{\mathrm{e}}=\frac{23300}{A=\left(n t_{f} E_{f}\right)^{.58}}
$$

The remaining factors can be obtained from two modification factors, $\mathrm{k}_{1}$ and $\mathrm{k}_{2}$. These two factors depend on the strength of the concrete and the wrapping

scheme:

$$
\begin{aligned}
& k_{1}=\left(\frac{\mathrm{Fc}}{27}\right)^{2 / 3} \\
& \mathrm{k}_{2}=\left(\mathrm{d}-\mathrm{L}_{\mathrm{e}}\right) / \mathrm{d} \quad(\text { three-sided wrap })
\end{aligned}
$$




$$
\mathrm{k}_{2}=\left(\mathrm{d}-2 \mathrm{~L}_{\mathrm{e}}\right) / \mathrm{d} \quad(\text { two-sided wrap })
$$

\subsubsection{British Concrete Society (BCS)}

The contribution of the FRP reinforcement can be determined by the following equation:

$$
v_{f}=E_{f} \varepsilon_{f e} A_{f} \frac{\left(\mathrm{d}-\frac{\mathrm{n}}{3} \mathrm{Lt}, \mathrm{max}\right)}{S_{f}}(\cos \beta+\sin \beta)
$$

where $\mathrm{E}_{\mathrm{f}}$ is the modulus of elasticity, $\varepsilon_{\mathrm{fe}}$ is the effective strain in the FRP reinforcement, $A_{f}$ is the area of the FRP reinforcement, $d$ is the effective depth of the FRP reinforcement measured from the compression zone of the member to the tensile reinforcement and $\mathrm{n}$ is 0 for a fully wrapped beam, 1.0 for a U-wrapped beam and 2.0 when the FRP is bonded to the sides. $\mathrm{Lt}$, $\max$ is the anchorage length required to develop full anchorage capacity:

$L t$,max $=0.7 * \sqrt{ }\left(E_{f} t_{f} / f_{c t m}\right)$, where $s_{f}$ is the longitudinal spacing of the FRP sheets used for strengthening, which is taken as 1.0 for continuous FRP sheets, and $\beta$ is the angle between the principal fibres of the FRP and a line perpendicular to the longitudinal axis of the member. The effective strain in the FRP reinforcement should be taken as the minimum of $\varepsilon_{\mathrm{fd}} / 2$, $0.64 \sqrt{ }\left(\mathrm{f}_{\mathrm{ctm}} / \mathrm{Ef}_{\mathrm{f}}\right)$ or 0.004 , where $\mathrm{f}_{\mathrm{ctm}}$ is the tensile strength of the concrete and $\varepsilon_{\mathrm{fd}}$ is the design ultimate strain capacity of the FRP reinforcement.

\subsubsection{Eurocode (EURO)}

The contribution of the FRP reinforcement can be determined by the following equation:

$$
\begin{aligned}
\mathrm{v}_{\mathrm{f}} & =.9 \varepsilon_{\mathrm{fk}, \mathrm{e}} / \Upsilon_{\mathrm{f}} \mathrm{E}_{\mathrm{f}} \rho_{\mathrm{f}} b_{\mathrm{w}} \mathrm{d}(1+\cot \beta) \sin \beta \\
\varepsilon_{\mathrm{fk}, \mathrm{e}} & =\alpha \varepsilon_{\mathrm{f}, \mathrm{e}} \leq \varepsilon_{\max }=005
\end{aligned}
$$

where $V_{\text {frp }}$ is the shear contribution of FRP, $\alpha$ is the reduction factor, $\beta$ is the angle of inclination of FRP fibres to the longitudinal axis of the member, $\varepsilon_{\max }$ is the maximum or limiting value of FRP strain $=0.005, b_{\mathrm{w}}=$ the width of the beam's cross section, $\mathrm{d}$ is the effective depth of the RC beam, $\Upsilon_{f}$ is the partial safety factor for FRP, $\varepsilon_{\mathrm{fk}, \mathrm{e}}$ is the characteristic effective FRP strain in the principal fibre direction and $\varepsilon_{\mathrm{f}, \mathrm{e}}$ is the effective tensile strain of FRP. \&f,e for U-wrapping and two-sided wrapping can be obtained by using minimum values between $\varepsilon_{\mathrm{fe}}=0.65\left(\mathrm{fc}^{2 / 3} / \mathrm{E}_{\mathrm{f}} \rho_{\mathrm{f}}\right)^{.56}$ and $\varepsilon_{\mathrm{fe}}=0.17\left(\mathrm{fc}^{2 / 3} / \mathrm{E}_{\mathrm{f}} \rho_{\mathrm{f}}\right)^{3 *} \varepsilon_{\mathrm{fu}}$, where $\mathrm{fc}$ is the cylinder compressive strength of concrete, $\varepsilon$ fu $=$ the ultimate tensile strain of the FRP composite and $\rho_{\mathrm{f}}=$ the FRP reinforcement ratio given by:

$$
\begin{aligned}
& \rho_{\mathrm{f}}=\left(2 n t_{\mathrm{f}} / \mathrm{b}_{\mathrm{w}}\right)\left(\mathrm{b}_{\mathrm{f}} / \mathrm{S}_{\mathrm{f}}\right) \quad \text { for FRP strips or sheets } \\
& \rho_{\mathrm{f}}=\left(2 n \mathrm{nt}_{\mathrm{f}} / \mathrm{b}_{\mathrm{w}}\right) \quad \text { for continuous sheets }
\end{aligned}
$$

Where $b_{f}=$ the width of FRP and $s_{f}$ is the spacing of FRP shear reinforcement.

\section{CONCLUSIONS}

1) The diagonal CFRP sheets provided better enhancement than the vertical CFRP sheets in ultimate load, deflection and crack width because tension forces are in same direction of fibre sheets direction.

2) Deep beams strengthened by U-shape CFRP sheets and diagonal CFRP sheets compared with control beam, the maximum increase in ultimate load by about $106 \%$.

3) Deep beams which strengthened by U-shape GFRP sheets and diagonal GFRP sheets compared with control beam, the maximum increase in ultimate load by about $81 \%$. 
4) Deep beams pre-cracked then repaired by diagonal CFRP and GFRP sheets compared with control beam, the increase in ultimate load by about $61 \%, 47.6 \%$ respectively.

5) Deep beams repaired by diagonal CFRP and GFRP sheets compared with beams strengthened by diagonal CFRP and GFRP sheets, the decrease in ultimate load by about 45 $\%, 33.7 \%$ respectively.

6) FRP sheets are considerably effective in delaying the initial appearance of shear cracks by improving the serviceability limit state of deep beams.

7) The proposed analytical model agrees well with the experimental results.

8) The analytical model from ACI and BCS didn't give good agreement with pre-cracked specimens because it gave higher values than experimental results and it is preferable to use the European code when repairing because it is more conservative.

\section{REFERENCES}

[1] M. R. Islam,M. A.Mansur, and M.Maalej, (2005)."Shear strengthening of RC deep beams using externally bonded FRP systems", Cement and Concrete Composites, vol. 27, no. 3, pp. 413-420.

[2] T. El Maaddawy and S. Sherif, (2009). "FRP composites for shear strengthening of reinforced concrete deep beams with openings", Composite Structures, vol. 89, no. 1, pp. $60-69$.

[3] Asghari, A.A., Tabrizian, Z., Beygi, M.H., Amiri, G.G. and Navayineya, B. (2014). An experimental study on shear strengthening of RC lightweight deep beams using CFRP. Journal of Rehabilitation in Civil Engineering, 2(2), 9-19.

[4] Mohammad Panjehpour, Hwa Kian Chai and Yen Lei Voo, (2014). "Strut Deformation in CFRP-Strengthened Reinforced Concrete Deep Beams", Scientific World Journal, Volume 2014, August 2014, Malaysia.

[5] M. Panjehpoura, A.A.A. Alia, Y.L. Voob and F.N. Aznietaa, (2014). "Modification of strut effectiveness factor for reinforced concrete deep beams strengthened with CFRP laminates", Materiales de Construcción, Vol. 64, Issue 314, April-June 2014, Malaysia

[6] Rafid Saeed Atea, (2015). "Shear Behavior of self-Compacting Concrete Deep Beams Strengthened with Carbon Fiber Reinforced Polymer Sheets", International Journal of Engineering Research \& Technology,Vol. 4, Issue 02, February-2015,Iraq.

[7] Zhang Z, Hsu C, Moren J. "Shear strengthening of reinforced concrete deep beams using carbon fiber reinforced polymer laminates". ASCE J Compos Constr2004, Vol.8, No.5, pp.403-414.

[8] F. Abed et al, (2012). "Shear characteristics of GFRP-reinforced concrete deep beams without web reinforcement ", Journal of Reinforced Plastics and Composites, Volume 31, No.16, pp.1063-1073.

[9] Khudair, J.A. and Atea, R.S. (2015). Shear behavior of self-compacting concrete deep beams strengthened with carbon fiber reinforced polymer sheets. International Journal of Engineering Research \& Technology (IJERT), 4(2), 187-191.

[10] H. K. Lee, S. H. Cheong, S.K.Ha, andC.G. Lee, (2013)."Behavior and performance of RC T-section deep beams externally strengthened in shear with CFRP sheets", Composite Structures, vol. 93, no. 2, pp. 911-922.

[11] Mohammed Mohammed Rasheed, (2016). "Retrofit of Reinforced Concrete Deep Beams with Different Shear Reinforcement by Using CFRP”, Civil and Environmental Research, vol. 8 , no.5, Iraq. 
[12] Muhammad Afaq Javed et al, (2016). “An Experimental Study on the Shear Strengthening of Reinforced Concrete Deep Beams with Carbon Fiber Reinforced Polymers", KSCE Journal of Civil Engineering, vol. 20, no.7, pp. 2802-2810.

[13] Dhahir, Mohammed Kareem. "Shear Strength of FRP Reinforced Deep Beams Without Web Reinforcement." Composite Structures 165 (April 2017): 223-232. doi:10.1016/j.compstruct.2017.01.039 